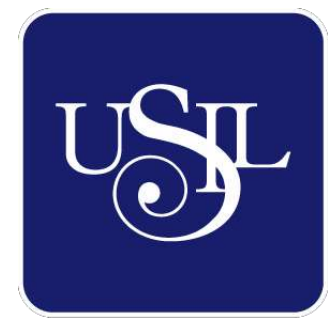

UNIVERSIDAD

SAN IGNACIO

DE LOYOLA

ESCUELA DE POSTGRADO

Maestría en Ciencias Empresariales

\title{
PLANEAMIENTO ESTRATÉGICO DE LA CLINICA CAYETANO HEREDIA
}

Trabajo de Investigación para optar el grado de Maestro en Ciencias Empresariales con Mención en Gestión Financiera

\section{VITTORIO JESÚS PESSAGNO VÍLCHEZ FRANCISCO JAVIER SANTA CRUZ RUBÍN DE CELIS MAGALLY DE LOS ÁNGELES TORDOYA MONTES JULY JESSICA VILLEGAS MOLLO}

Asesor:

Edmundo Rafael Casavilca Maldonado

Lima - Perú

2019 


\section{RESUMEN EJECUTIVO}

Este Plan Estrategico ha sido desarrollado para la Clinica Médica Cayetano Heredia para el periodo de tiempo comprendido entre los años 2017-2019 y busca dar los lineamientos necesarios para mantener su ventaja competitiva en el tiempo.

Con nuestra propuesta buscamos incrementar la participación de mercado, llegar a ser los líderes, incrementar los márgenes de rentabilidad esperada por sus accionistas, y seguir ofreciendo mejores servicios médicos en beneficio de la población de Lima Norte.

Se ha realizado un análisis del entorno, así como de los procesos internos y a todo lo que competen a la industria de la salud. Se desarrollaron matrices que mejoran la posición de la clínica frente a sus competidores, mejoran las relaciones bilaterales con los stakeholders, y se identifican a los grupos de interés presentes alrededor de la clínica, a quienes se ha incluido en este plan estratégico.

El presente plan propone una estrategia de penetración de mercado; y como estrategia contingente desarrollo de mercado y desarrollo de producto, para ello se implementan 15 iniciativas, las cuales cubren los principales problemas identificados.

La iniciativas planteadas permitiran alcanzar los 6 objetivos estratégicos establecidos los cuales fueron formulados de acuerdo a lo planteado en la visión y misión propuestas, y permiten desarrollar estrategias para satisfacer a todos los grupos de interes involucrados.

1. Formación de un equipo de trabajo compuesto por profesionales y técnicos de la salud altamente calificados. 
2. Lograr la satisfacción de los pacientes de Lima Norte a través de una atención personalizada.

3. Generar la rentabilidad esperada por los accionistas.

4. Estar a la vanguardia de la tecnología y equipos médicos.

5. Creación e implementación de infraestructura que facilite el circuito de atención a los pacientes de la clínica.

6. Implemetación de sistema de seguimiento a la atención de los pacientes para asegurar la calidad y continua mejora.

Partiendo de los objetivos estratégicos propuestos, las estrategias que se desprenden con mayor ponderación son:

1. Posicionar a la Clínica Cayetano Heredia en la zona de Lima Norte.

2. Implementación de sistema de seguimiento a pacientes.

3. Desarrollo de mercado en la zona de Lima Norte. (Cultura saludable)

4. Desarrollo de mercado para el segmento de atención médica privada en la zona de Lima Norte.

5. Desarrollo de servicios que complementen la atención médica.

El posicionamiento de la Clínica fue la estrategia específica con mayor ponderación y se ha estimado que la implementacion necesaria para ejecutarla requerirá de un financiamiento externo de S/ 446, 100.00 por medio del préstamo de un banco, un equivalente al 46.63\% del total de la inversión (S/ 956, 700.00).

Finalmente de acuerdo a los estados de resultados proyectados presentados y las demás proyecciones financieras, es factible aprobar dicha inversión por los resultados favorables que se obtendrán en el periodo de tiempo establecido. 
Por lo expuesto, recomendamos se lleve a cabo la implementacion del plan estratégico que proponemos, ya que permitirá que la Clínica Médica Cayetano Heredia mantenga su ventaja competitiva, incrementar su participación en el mercado e incrementar los márgenes económicos. 